\title{
What Motivates Wheelchair Basketball Spectators? Analysis of Moderating Effects on Intention to Attend Tokyo 2020 Olympic Paralympic Games
}

\author{
Rei Yamashita ${ }^{1}$ and Masaya Muneda ${ }^{2}$ \\ ${ }^{1}$ Faculty of Human Life Design, Toyo University \\ 48-1, Oka, Asaka-City, Saitama, 351-8510, Japan \\ yamashita081@toyo.jp \\ ${ }^{2}$ Faculty of Human Health Science, Kanazawa Gakuin University \\ 10, Suemachi, Kanazawa, Ishikawa, 920-1302, Japan \\ [Received March 28, 2019; Accepted August 8, 2019; Published online August 27, 2019]
}

\begin{abstract}
In 2013, the International Olympic Committee announced that the 2020 Summer Paralympic Games will be held in Tokyo for their second time. Despite the enthusiasm toward disabled sport or Paralympic games, whether citizens will watch the Paralympic games at sport facilities remains to be determined. Increasing the number of spectators and supporters is critical to attract new sponsors and gain additional revenue.

The objectives of this study are two-fold. First, it reveals spectators' demographic attributes and, second, using the Motivational Scale for Disability Sport Consumption (MSDSC), it tests for moderating effects on future intentions to spectate the 2020 Tokyo Olympic Paralympic Games. Researchers distributed questionnaires to spectators who attended the 46th Japan Wheelchair Basketball Championship Emperor's Cup on May 19, 2018 (499 valid samples) and May 20, 2018 (487 valid samples). A confirmatory factor analysis (CFA) eliminated two items from the model. Next, a multiple regression analysis is conducted to test the relationship between spectator motivation and intention to attend a mega sporting event. The results highlight that there is a considerable difference in the effect of the three moderator variables. In conclusion, it is imperative for practitioners to inform spectators about the uniqueness and singularity of wheelchair basketball.
\end{abstract}

Keywords: motivations, wheelchair basketball, spectators, mega sporting events

\section{Introduction}

In 2020, Tokyo will host the Summer Paralympic for their second time. Given that the event is scheduled to be held in less than a year, resident interest in disabled sport has increased by $12 \%$ over the last three years (Tokyo Metropolitan Government, 2018). Moreover, the experience of spectating a disabled sport has increased by $6 \%$. However, the percentage of individuals who have watched a game at a sport venue is a mere $3 \%$ and the intention to observe the Tokyo 2020 Olympic Paralympic Games at the venue remains very low. Residents prefer viewing or listening to the game using mass media channels, such as television, radio, or the Internet.

Shapiro et al. (2012) highlight the importance of sport management students receiving a well- rounded education of the sport business industry, including disabled sport. Shapiro and Pitts (2014) review the literature on disability sport in sport business management journals and determine that only 89 articles (or less than $1 \%$ of the total) were published during 2002 - 2012, and a majority of the research focuses on sociocultural aspects (43\%) and a few in the sport marketing field address COSMA standards $(6 \%)$. The authors conclude that the discipline of sport management falls short of providing new knowledge on people with disabilities. Thus, they emphasize the need for practitioners and researchers to collaborate and fill the research gap in disability sport management. Given the booming interest in disabled sport in Tokyo, both practitioners and researchers must focus on identifying spectators to create an efficient marketing strategy for 
the Tokyo 2020 Paralympic Games and thereafter. The objectives of this study are two-fold. First, it seeks to reveal the wheelchair basketball spectators' demographics attributes, and, second, it aims to test the moderating effects on the intention to spectate the Tokyo 2020 Olympic Paralympic Games using the Motivational Scale for Disability Sport Consumption (MSDSC).

\section{Literature Review}

\subsection{Motivation in non-disabled and disabled sport settings}

A central issue for management organizations is to understand their customers; a failure to do so could lead to a failure to understand who the customers are and a faulty marketing strategy. Numerous studies have highlighted the importance of understanding sport consumers from a psychological perspective (e.g., Funk et al., 2001; Matsuoka, 2012; Trail and James, 2001). Several works have adapted a mainstream motivational scale to create new ones, particularly when a new sport context emerges, which makes it critical to identify consumers in the sport market (Cottingham et al., 2012; Kwon and Trail, 2001). For example, Funk et al. (2001) apply a revised Sport Interest Inventory (SII) to a women's sporting event by including "supporting women's opportunity in sport" from the original SII. This line of thinking has also been introduced in disabled sport settings. Drawing on Trail and James' (2001) Motivation Scale for Sport Consumption (MSSC), Byon et al. (2010) establish a motivational scale to measure the number of wheelchair rugby spectators. The authors list the following seven factors as part of the motivational scale: drama, aesthetics, vicarious achievement, escape, social interaction, knowledge, and physical skill. Further, they apply the scale to test the independent variable and its influence on repatronage intention and online media consumption. Their results reveal that physical skill, knowledge, and vicarious achievement positively affect the dependent variable. While their research contributes to the discussion on disabled sport spectatorship, they use a motivational scale generally applied to a non-disabled sport setting; thus, the scale lacks the uniqueness of the rationale of disabled sport.

According to Byon et al. (2010), who test the usefulness of MSSC by examining spectators' motivation to attend wheelchair rugby events (Byon et al., 2010), Cottingham et al.'s (2014) study is the only one to identify the unique context of disabled sport. Given the unique and singular rationale of disabled sport, Cottingham et al. (2014) conclude that discussions with practitioners are needed to better understand consumer behavior in the context of disabled sport. They develop the MSDSC, comprising eight factors and 28 items, to examine spectators of a national-level collegiate wheelchair basketball championship. The original factors introduced in their research include "supercrip image" and "inspiration." When individuals with a disability engage in a superhuman act to overcome the disability or society in an unexpected manner, they are said to have a supercrip image (Gliedman and Roth, 1980). Inspiration, another dominant original variable, is defined as "an external experience that upon being internalized leads to behavior change" (Thrash and Elliott, 2003). Cottingham et al. (2014) adopt these two variables in their scale and make an understandable contribution to the disabled sport literature. Nevertheless, they emphasize the need to apply the MSDSC to various settings to validate and improve the scale. Importantly, Cottingham et al. (2014) state that knowing the factors that motivate disability sport spectators is not enough. For the MSDSC to be an effective marketing tool, both practitioners and researchers must better understand ways to increase the market share of disabled sport by, for example, conducting an additional statistical test that uses a dependent variable or accounts for moderating effects.

\subsection{Moderating effects in sport marketing research}

Studies have overlooked the relationship between spectators' motivation and behavioral intentions and, in particular, sport management researchers have failed to account for the effects of moderating variables on sport consumers' decision making (Yoshida and Gordon, 2012). Nevertheless, in recent years, marketing researchers have turned their attention toward moderators. A significant body of research suggests that demographic (e.g., gender, age, and household income), relational (e.g., loyalty program participation), and psychological (e.g., product involvement and commitment) moderators are three main types of groups that contain poten- 
tial moderating variables (Seiders et al., 2005). Among those in demographics, gender is widely used as a moderating variable in marketing research (Saad and Gill, 2000) possibly because males tend to establish a stronger satisfaction-repurchase behavior relationship than females (Mittal and Kamakura, 2001). That is, males who are satisfied with a product are more likely to repurchase it than females (Homburg and Giering, 2001).

Relational characteristics is another moderating group deemed crucial to understand customers. Yoshida and Gordon (2012), for example, suggest that season-ticket holders tend to have a stronger customer equity-loyalty relationship than those who do not have it. Adopting Bloemer and Ruyter's (1998) rationale that highly experienced individuals will be more aware of their experiences when making an evaluation, Velázquez et al. (2010) examine consumers' previous experiences with a product or service. Byon et al. (2010) introduce another relational moderating variable - the disability itself that warrants testing; it may be a moderating factor, whose role in disabled sport consumption behavior requires further investigation. Based on the literature review, we test three moderating effects: gender, whether a spectator is a repeat or novice viewer of a disabled sport, and having a close friend or family member with a disability.

\section{Methods}

\subsection{Data collection and sample}

The scale was originally drafted in English and then translated into Japanese by a bilingual English professor. Next, two researchers and three wheelchair basketball practitioners discussed and checked the phrasing of each item. A questionnaire survey was administered to spectators at the 46th Japan Wheelchair Basketball Championship Emperor's Cup held in Tokyo during May 19 - 20, 2018. The researchers used a convenient sampling method stratified by age and gender. Well-trained surveyors visited each seating section to obtain an accurate estimate of the spectators' gender and age. Of the 1,023 questionnaires that were distributed, 998 were returned (a response rate of $97.5 \%$ ); of these, 12 were rejected because of missing data. The final usable response rate was $98.7 \%(n=986)$.

\subsection{Measurement and data analysis}

This study adopts Cottingham et al.'s (2014) motivational scale along with a seven-point Likert scale, where responses range from " $1=$ least important" to " $7=$ most important." A confirmatory factor analysis (CFA) and stepwise multiple regression analysis are conducted. CFA is used to evaluate the measurement model. The overall fit of the model is estimated using the following fit indexes: ratio of chi-square to degree of freedom $\left(\chi^{2} / \mathrm{df} \leqq\right.$ 5.00, Bollen, 1989); comparative fit index (CFI $\geqq .90, \mathrm{Hu}$ and Bentler, 1999); Tucker-Lewis index (TLI $\geqq .90, \mathrm{Hu}$ and Bentler, 1999); and root mean square error of approximation (RMSEA $\leqq .080, \mathrm{Hu}$ and Bentler, 1999). The measurement model is further assessed by examining factor loadings, average variance extracted (AVE), and construct reliability (CR) (Hair et al., 2010). The threshold for factor loading (Hair et al., 2010), CR, and AVE (Fornell and Larcker, 1981; Verhoef et al., 2002) is .50, .60, and .40 , respectively. In addition, discriminant validity is calculated by assessing whether the correlation coefficients on the items are smaller than the square root of the AVE values. The data are analyzed using SPSS (version 24.0) and Amos (version 24.0).

\section{Results}

Of the 986 spectators, $42.3 \%$ are males and $57.7 \%$ are females. The average age of the spectators was $39(\mathrm{SD}=14.53)$ years. In addition, $54.5 \%$ of the spectators are from Tokyo and $45.5 \%$ are from outside of Tokyo. Finally, $47.8 \%$ spectators have a family member or close friend with a disability and $48.0 \%$ have watched a disabled sport at the venue (Table 1).

CFA is conducted on the first half of the valid sample $(n=499)$ to evaluate the measurement model. The factor loading for "I enjoy watching wheelchair basketball players achieve more than is expected of them" was .48 and "I enjoy the rough and physical nature of wheelchair basketball" was .45 ; because both were below the threshold, they were eliminated from the second round of CFA. According to the second CFA on the same sample, the factor loadings for all the indicators are above the threshold and all model indexes report a good fit $\left(\chi^{2} / \mathrm{df}=3.73, \mathrm{CFI}=.90, \mathrm{TLI}=.87\right.$, 
Table 1 Variables and summary statistics.

\begin{tabular}{|c|c|c|c|c|c|c|c|}
\hline & & $\mathrm{n}$ & $\%$ & & & $\mathrm{n}$ & $\%$ \\
\hline \multirow{2}{*}{ Gender } & Male & 408 & 42.3 & \multirow{3}{*}{$\begin{array}{l}\text { Residence } \\
\text { status }\end{array}$} & \multirow{3}{*}{$\begin{array}{c}\text { Tokyo } \\
\text { Outside of } \\
\text { Tokyo }\end{array}$} & 460 & 54.5 \\
\hline & Female & 557 & 57.7 & & & 384 & 45.5 \\
\hline \multirow{7}{*}{$\begin{array}{c}\text { Age } \\
(\text { avg. } 39.95 \\
\mathrm{SD}=14.53)\end{array}$} & 10 's & 47 & 5.0 & & & & \\
\hline & 20 's & 226 & 23.9 & \multirow{3}{*}{$\begin{array}{l}\text { Family/Close } \\
\text { friend with } \\
\text { disability }\end{array}$} & \multirow{3}{*}{$\begin{array}{l}\text { Yes } \\
\text { No }\end{array}$} & \multirow{3}{*}{$\begin{array}{l}456 \\
497\end{array}$} & \multirow{3}{*}{$\begin{array}{l}47.8 \\
52.2\end{array}$} \\
\hline & 30 's & 202 & 21.4 & & & & \\
\hline & 40 's & 22 & 24.0 & & & & \\
\hline & 50 's & 152 & 16.1 & \multirow{3}{*}{$\begin{array}{l}\text { Spectating } \\
\text { Experience }\end{array}$} & \multirow{3}{*}{$\begin{array}{l}\text { Yes } \\
\text { No }\end{array}$} & \multirow{3}{*}{$\begin{array}{l}465 \\
503\end{array}$} & \multirow{3}{*}{$\begin{array}{l}48.0 \\
52.0\end{array}$} \\
\hline & 60 's & 64 & 6.8 & & & & \\
\hline & 70 's & 26 & 2.8 & & & & \\
\hline
\end{tabular}

Table 2 Results of confirmatory factor analysis.

\begin{tabular}{|c|c|c|c|}
\hline Inspiration & M & SD & Lamda \\
\hline 1 Live a more active life & 3.82 & 1.54 & .50 \\
\hline 2 Inspires me to approach differently & 4.45 & 1.65 & .65 \\
\hline 3 There is something bigger than life & 4.02 & 1.68 & .76 \\
\hline 4 Engage in life in a different way & 4.10 & 1.67 & .83 \\
\hline \multicolumn{4}{|l|}{ Supercrip Image } \\
\hline 5 Players overcome their disabilities & 4.69 & 1.75 & .75 \\
\hline 6 Players overcome social barriers & 4.42 & 1.73 & .89 \\
\hline \multicolumn{4}{|l|}{ Physical Skill } \\
\hline 7 Appreciate the superior skills & 5.58 & 1.37 & .50 \\
\hline 8 Appreciate the beauty inherent & 5.41 & 1.40 & .72 \\
\hline 9 Enjoy watching well-executed performance & 5.18 & 1.43 & .79 \\
\hline 10 Enjoy gracefulness of the game & 5.04 & 1.48 & .75 \\
\hline \multicolumn{4}{|l|}{ Violence and Aggression } \\
\hline 11 Enjoy the hostility & 4.07 & 1.65 & .84 \\
\hline 12 Knocked to the ground & 2.53 & 1.61 & .67 \\
\hline 13 Enjoy aggressive play & 4.16 & 1.79 & .50 \\
\hline \multicolumn{4}{|l|}{ Acquisition of Knowledge } \\
\hline 14 Know names of the players & 4.25 & 2.41 & .70 \\
\hline 15 Know the rules of the game & 4.18 & 1.92 & .90 \\
\hline 16 Know the results of the game & 3.71 & 2.10 & .81 \\
\hline \multicolumn{4}{|l|}{ Escape } \\
\hline 17 Provides "life's little problem" for me & 4.26 & 1.68 & .62 \\
\hline 18 Escape from day-to-day routine & 3.56 & 1.76 & .85 \\
\hline 19 Distraction from everyday activities & 3.99 & 1.68 & .81 \\
\hline \multicolumn{4}{|l|}{ Social Interaction } \\
\hline 20 Interacting with other people & 4.08 & 1.63 & .69 \\
\hline 21 Socializing with other people & 3.93 & 1.62 & .77 \\
\hline 22 Talking with other people & 3.67 & 1.64 & .84 \\
\hline \multicolumn{4}{|l|}{ Physical Attractiveness } \\
\hline 23 Individual players as "sex appeal" & 3.16 & 1.85 & .65 \\
\hline 24 Players physically attractive & 3.83 & 1.66 & .83 \\
\hline 25 Enjoy watching physically attractive players & 3.92 & 1.76 & .74 \\
\hline
\end{tabular}

Note: Chi-square $/ \mathrm{df}=3.73, \mathrm{CFI}=.90, \mathrm{TLI}=.87, \mathrm{RMSEA}=.07$ 
RMSEA =.07) (see Table 2). The scale comprises eight factors and 25 items.

The scale is finalized using the second half of the valid sample $(n=487)$. All factor loadings are above the threshold and the indexes have an acceptable fit to the data $\left(\chi^{2} / \mathrm{df}=3.66, \mathrm{CFI}=.90, \mathrm{TLI}=.87\right.$, RMSEA $=.07)$. Next, convergent validity and reliability of the measurement scale are calculated. The recommended level for CR is .60 (Hair et al., 2010) and that for AVE is .40 (Verhoef et al., 2002). The AVEs for all the factors range between .48 and .78, which are above the threshold, and $\mathrm{CR}$ varies from .74 to .91 . Thus, the reliability and convergent validity are confirmed (Table 3 ).

Furthermore, discriminant validity is tested by comparing the indicators' correlation coefficients with the AVE. Table 4 shows that the AVE of each factor, except inspiration and violence and aggression, is greater than the correlation coefficient of each variable. Since discriminant validity does not deviate much from the criteria and remains unclear, we conclude that the motivational scale for the spec-

Table 3 Results of confirmatory factor analysis.

\begin{tabular}{|c|c|c|c|c|c|}
\hline Inspiration & M & SD & Lamda & AVE & CR \\
\hline Live a more active life & 3.83 & 1.51 & .59 & \multirow{4}{*}{.48} & \multirow{4}{*}{.78} \\
\hline 2 Inspires me to approach differently & 4.48 & 1.61 & .57 & & \\
\hline 3 There is something bigger than life & 4.02 & 1.66 & .75 & & \\
\hline 4 Engage in life in a different way & 4.18 & 1.62 & .82 & & \\
\hline \multicolumn{6}{|l|}{ Supercrip Image } \\
\hline 5 Players overcome their disabilities & 4.71 & 1.76 & .77 & \multirow{2}{*}{.71} & \multirow{2}{*}{.83} \\
\hline 6 Players overcome social barriers & 4.44 & 1.73 & .91 & & \\
\hline \multicolumn{6}{|l|}{ Physical Skill } \\
\hline Appreciate the superior skills & 5.62 & 1.28 & .55 & \multirow{4}{*}{.63} & \multirow{4}{*}{.83} \\
\hline 8 Appreciate the beauty inherent & 5.38 & 1.41 & .81 & & \\
\hline 9 Enjoy watching well-executed performance & 5.16 & 1.45 & .80 & & \\
\hline 10 Enjoy gracefulness of the game & 5.07 & 1.46 & .78 & & \\
\hline \multicolumn{6}{|l|}{ Violence and Aggression } \\
\hline 11 Enjoy the hostility & 4.06 & 1.61 & .74 & \multirow{3}{*}{.49} & \multirow{3}{*}{.74} \\
\hline 12 Knocked to the ground & 2.55 & 1.58 & .74 & & \\
\hline 13 Enjoy aggressive play & 4.09 & 1.80 & .62 & & \\
\hline \multicolumn{6}{|l|}{ Acquisition of Knowledge } \\
\hline 14 Know names of the players & 4.04 & 2.38 & .88 & \multirow{3}{*}{.78} & \multirow{3}{*}{.91} \\
\hline 15 Know the rules of the game & 4.12 & 1.93 & .92 & & \\
\hline 16 Know the results of the game & 3.68 & 2.10 & .85 & & \\
\hline \multicolumn{6}{|l|}{ Escape } \\
\hline 17 Provides "life's little problem" for me & 4.37 & 1.60 & .69 & \multirow{3}{*}{.62} & \multirow{3}{*}{.83} \\
\hline Escape from day-to-day routine & 3.56 & 1.72 & .82 & & \\
\hline 19 Distraction from everyday activities & 4.06 & 1.67 & .85 & & \\
\hline \multicolumn{6}{|l|}{ Social Interaction } \\
\hline 20 Interacting with other people & 4.08 & 1.65 & .79 & \multirow{3}{*}{.70} & \multirow{3}{*}{.88} \\
\hline Socializing with other people & 3.87 & 1.65 & .90 & & \\
\hline Talking with other people & 3.64 & 1.65 & .83 & & \\
\hline \multicolumn{6}{|l|}{ Physical Attractiveness } \\
\hline 23 Individual players as "sex appeal" & 3.17 & 1.80 & .62 & \multirow{3}{*}{.53} & \multirow{3}{*}{.77} \\
\hline Players physically attractive & 3.86 & 1.61 & .74 & & \\
\hline Enjoy watching physically attractive players & 3.83 & 1.73 & .81 & & \\
\hline
\end{tabular}

Note: Chi-square $/ \mathrm{df}=3.66, \mathrm{CFI}=.90, \mathrm{TLI}=.87, \mathrm{RMSEA}=.07$ 
Table 4 Comparison of correlation coefficient and average variance extracted.

\begin{tabular}{ccccccccc}
\hline & INS & SI & PS & VA & AK & ESC & INT & PA \\
\hline INS & $.47 \mathrm{a}$ & & & & & & & \\
SI & .34 & $.71 \mathrm{~b}$ & & & & & & \\
PS & .19 & .08 & $.63 \mathrm{c}$ & & & & & \\
VA & .28 & .13 & .14 & $.49 \mathrm{~d}$ & & & & \\
AK & .03 & .00 & .28 & .09 & $.76 \mathrm{e}$ & & & \\
ESC & .75 & .17 & .13 & .32 & .05 & $.62 \mathrm{f}$ & & \\
INT & .45 & .17 & .17 & .35 & .06 & .34 & $.70 \mathrm{~g}$ & \\
PA & .30 & .25 & .25 & .65 & .12 & .24 & .29 & $.53 \mathrm{~h}$ \\
\hline
\end{tabular}

Note: $a=$ Inspiration AVE, $b=$ Supercrip Image AVE, $c=$ Physical Skill AVE, d = Violence Aggression AVE, e = Acquisition of Knowledge AVE, $\mathrm{f}=$ Escape AVE, $\mathrm{g}=$ Social Interaction AVE, $\mathrm{h}=$ Physical Attractiveness AVE

tators of Japanese wheelchair basketball can be explained by the following factors: inspiration, supercrip image, physical skill, violence and aggression, knowledge acquisition, escape, social interaction, and physical attractiveness.

In sum, the CFA results empirically show that the motives of disabled sport spectators can be explained by the eight factors adopted from Cottingham et al.'s (2014) scale; however, in our study, we eliminate two items from the original scale.

Next, an analysis using several moderating items is conducted to test which motivating factor has the highest influence on the intention to spectate the mega sporting event. Accordingly, three moderators are assessed: gender, whether spectators have a close friend or family member with a disability, and regular attendees of disabled sport events at the venue versus novice spectators. A stepwise multiple regression analysis is conducted on the second half of the sample $(n=487)$ to assess the relationship between spectators' motivation and intention to attend the upcoming mega sporting event in Tokyo. A gender - based comparison reveals that physical skill $\left(\beta_{\text {male }}=.49, \mathrm{p}<.001\right)$ positively affects the dependent variable for male spectators, whereas both physical skill $\left(\beta_{\text {female }}=.24, \mathrm{p}<.001\right)$ and acquisition of knowledge $\left(\beta_{\text {female }}=.20, \mathrm{p}<.001\right)$ positively affect the dependent variable for female spectators. The adjusted $\mathrm{R}$ square for male and female spectators was $24 \%$ and $11 \%$, respectively (Table 5).
Table 5 Comparison of male versus female.

\begin{tabular}{|c|c|c|c|c|}
\hline Independent Variables & beta & $\begin{array}{l}\text { Male } \\
\text { significance }\end{array}$ & beta & $\begin{array}{l}\text { Female } \\
\text { significance }\end{array}$ \\
\hline Inspiration & & n.s. & & n.s. \\
\hline Supercrip Image & & n.s. & & n.s. \\
\hline Physical Skill & .49 & $* * *$ & .24 & $* * *$ \\
\hline Violence and Aggression & & n.s. & & n.s. \\
\hline Acquisition of Knowledge & & n.s. & .20 & $* * *$ \\
\hline Escape & & n.s. & & n.s. \\
\hline Social Interaction & & n.s. & & n.s. \\
\hline Physical Attractiveness & & n.s. & & n.s. \\
\hline Adj R square & & .24 & & .11 \\
\hline
\end{tabular}

Note: $* * * \mathrm{p}<.001$, dependent variable: Intention to attend Tokyo 2020 Games

For spectators who have a family member or close friend with a disability, acquisition of knowledge $\left(\beta_{\text {disabled member }}=.27, \mathrm{p}<.01\right)$ and inspiration $\left(\beta_{\text {disabled member }}=.20, \mathrm{p}<.05\right)$ have a positive impact on the future intention to spectate Tokyo 2020 Games, explaining 14\% of the model. For those who do not have a family member or close friend with a disability, inspiration $\left(\beta_{\text {no disabled members }}=.50\right.$, $\mathrm{p}<.001)$ has a stronger positive effect on the intention to attend the 2020 mega sporting event. In contrast, physical attractiveness $\left(\beta_{\text {no disabled members }}=\right.$ $-.15, \mathrm{p}<.05)$ has a negative effect, explaining $20 \%$ of the model (Table 6).

Table 6 Comparison of having a disability member versus not having disability member.

\begin{tabular}{lcccc}
\hline & \multicolumn{2}{c}{$\begin{array}{c}\text { Disabled } \\
\text { members }\end{array}$} & \multicolumn{2}{c}{$\begin{array}{c}\text { No disabled } \\
\text { members }\end{array}$} \\
Independent Variables & beta $\begin{array}{c}\text { significance } \\
\text { beta }\end{array}$ significance \\
\hline Inspiration & .20 & $*$ & .50 & $* * *$ \\
Supercrip Image & & n.s. & & n.s. \\
Physical Skill & & n.s. & & n.s. \\
Violence and Aggression & n.s. & & n.s. \\
Acquisition of Knowledge & .27 & $* *$ & & n.s. \\
Escape & & n.s. & & n.s. \\
Social Interaction & & n.s. & & n.s. \\
Physical Attractiveness & & n.s. & -.15 & $*$ \\
Adj R square & & .14 & & .20 \\
\hline
\end{tabular}

Note: ${ }^{*} \mathrm{p}<.05, * * \mathrm{p}<.01, * * * \mathrm{p}<.001, \mathrm{n} . \mathrm{s} .=$ not significant, dependent variable: Intention to attend Tokyo 2020 Games

Finally, this study examines those who have watched a game at the venue and those who have not as a moderator variable. For those who have watched a game at the venue in the past, inspiration 
$\left(\beta_{\text {repeater }}=.32, \mathrm{p}<.001\right)$ and acquisition of knowledge $\left(\beta_{\text {repeater }}=.18, \mathrm{p}<.05\right)$ positively affect the dependent variable. On the other hand, for novice spectators, inspiration $\left(\beta_{\text {novice }}=.42, \mathrm{p}<.001\right)$ resulted giving positive impact, however physical attractiveness performed a significant negative effect $\left(\beta_{\text {novice }}=-.18, \mathrm{p}<.01\right)$. The adjusted $\mathrm{R}$ square for repeater and novice spectators was $18 \%$ and $15 \%$, respectively (Table 7 ).

Table 7 Comparison of repeater versus novice.

\begin{tabular}{|c|c|c|c|c|}
\hline Independent Variables & beta & $\begin{array}{l}\text { Repeater } \\
\text { significance }\end{array}$ & beta & $\begin{array}{l}\text { Novice } \\
\text { significance }\end{array}$ \\
\hline Inspiration & .32 & $* * *$ & .42 & $* * *$ \\
\hline Supercrip Image & & n.s. & & n.s. \\
\hline Physical Skill & & n.s. & & n.s. \\
\hline Violence and Aggression & & n.s. & & n.s. \\
\hline Acquisition of Knowledge & .18 & $*$ & & n.s. \\
\hline Escape & & n.s. & & n.s. \\
\hline Social Interaction & & n.s. & & n.s. \\
\hline Physical Attractiveness & & n.s. & -.18 & $* *$ \\
\hline Adj R square & & .18 & & .15 \\
\hline
\end{tabular}

Note: ${ }^{*} \mathrm{p}<.05, * * \mathrm{p}<.01, * * * \mathrm{p}<.001, \mathrm{n} . \mathrm{s} .=$ not significant, dependent variable: Intention to attend Tokyo 2020 Games
Table 8 summarizes the results for the moderating effects. First, in terms of gender, physical skill has a positive impact on both male and female spectators' intention to watch a mega sporting event at the venue; however, the positive impact of knowledge acquisition is observed only for female spectators. Second, inspiration and knowledge acquisition have a strong impact on the dependent variable for those who have a close friend or family member with a disability. Finally, physical attractiveness has a significantly negative effect on those who do not have a close friend or family member with a disability and novice spectators.

\section{Discussion and limitations}

This study aims to reveal the factors motivating wheelchair basketball spectators, and using the MSDSC, to examine the moderating effects of gender, experience spectating disabled sport, and having a family or close friend with a disability. Given the limited number of studies focusing on disabled sport from a sport marketing perspective, this study provides empirical evidence from both theoretical

Table 8 Summarizing the results of the moderating effects.

\begin{tabular}{|c|c|c|c|c|c|c|}
\hline & Male & Female & Disability & No Disability & Repeater & Novice \\
\hline $\operatorname{Adj} \mathrm{R}^{2}$ & .24 & .11 & .14 & .20 & .18 & .15 \\
\hline Inspiration & n.s. & n.s. & + & + & + & + \\
\hline Supercrip Image & n.s. & n.s. & n.s. & n.s. & n.s. & n.s. \\
\hline Physical Skill & + & + & n.s. & n.s. & n.s. & n.s. \\
\hline Violence & n.s. & n.s. & n.s. & n.s. & n.s. & n.s. \\
\hline Knowledge & n.s. & + & + & n.s. & + & n.s. \\
\hline Escape & n.s. & n.s. & n.s. & n.s. & n.s. & n.s. \\
\hline Interaction & n.s. & n.s. & n.s. & n.s. & n.s. & n.s. \\
\hline Attractiveness & n.s. & n.s. & n.s. & - & n.s. & - \\
\hline
\end{tabular}

Note: $+=$ significantly positive effect, $-=$ significantly negative effect, n.s. $=$ not significant

and practical viewpoints.

First, we examine the characteristics of wheelchair basketball spectators. A key finding is that the number of female spectators $(57.7 \%)$ is greater than male ones $(42.3 \%)$. On comparing with the attendance of female spectators in other professional sport in Japan, it is found that they constitute 34\%, $31.5 \%$, and $31.4 \%$ of the spectators in professional baseball, football, and basketball, respectively (Azrena, 2017). Another key finding is that those in their 20's (23.9\%) account for the largest group of spectators for wheelchair basketball (23.9\%); this indicates that the age of the majority of spectators for disabled sport is lower than that for other sport (those in their 20's account for 17.5\%, 16.0\%, and $17.7 \%$ of the spectators for baseball, football, and basketball, respectively) (Azrena, 2017). Thus, we can conclude that young females constitute a majority of the spectators at wheelchair basketball events in Japan.

Additional distinctive results reveal that spectators demonstrate considerable interest in disabled 
and disabled sport. As many as $52.2 \%$ of the spectators have a close friend or family member with a disability; however, the percentage of those with a disability in Japan is $7.4 \%$ of the entire population (Ministry of Health, Labour and Welfare, 2018). In addition, more than half of the spectators (52\%) have watched a game at the venue and, on comparing this number with the number reported from the Tokyo Government (2018), only $2.7 \%$ of the population has watched a game at the venue. These percentages imply that since they are the parties concerned, they have a strong interest toward disability sport and tend to attend the game. A quick glance at the demographic aspects of wheelchair basketball spectators reveals that they are a rarity in the sport marketing field.

In order to test the moderating effects on the intention to spectate the Tokyo 2020 Olympic Paralympic Games, the MSDSC scale is first tested on Japanese spectators. To adapt to the Japanese population, two items are eliminated from the original MSDSC. The highest mean score is estimated for physical skill, which contains items related to the uniqueness of wheelchair basketball (Table 3). In other words, physical skill lures spectators to view wheelchair basketball.

Despite the measurement scale having an appropriate model fit, certain issues have been encountered with discriminant validity: the inspiration AVE is lower than the correlation coefficient on escape and the AVE for violence aggression is lower than the correlation coefficient on physical attractiveness. This can be attributed to the strong correlation between inspiration and escape, as well as that between physical attractiveness and violence. Furthermore, because inspiration is defined as "an external experience that upon being internalized leads to behavior change" (Thrash and Elliott, 2003), this result can be explained by the strong relationship with escape motivation. Spectators without a physical defect cannot feel or live like those with a disability. Nevertheless, watching those with a disability on the court may help spectators forget their own stress and could challenge them in their everyday life. Violence and physical attractiveness depend on the athletes' disability; this could be related to the fact that the spectators had similar feelings when they were asked about the motivation to spectate wheelchair basketball.

In order to satisfy the second objective of this study, regression analyses were conducted and revealed that the following three moderators play an adequate role in explaining the strong relationship between spectator motivation and intention to attend a mega sporting event: gender; being a repeater or novice spectator of a disabled sport; and having a family member or close friend with a disability. In terms of gender, physical skill has a strong impact on both male and female spectators' intention to attend the mega sporting event, whereas knowledge acquisition has an effect only on female spectators. Dietz-Uhler et al. (2000) stated that male and female spectators become sport fans for different reasons: females do so to socialize and males enjoy acquiring more knowledge about sport through spectating. However, this study suggested vise-versa; female spectators are more motivated by acquiring knowledge about sport than male spectators. This could be supported by the fact that female spectators have a sense of responsibility to empower other people with disability (Ashton-Shaeffer et al., 2001). In addition, this study suggests that physical skill influenced both genders possibly because wheelchair basketball was a unique sport setting for most of the spectators. Gender used as a moderating effect suggests that gender differences in service evaluation vary by event type. In the case of disabled sport, females are more concerned about factors motivating them to attend a mega sporting event.

A comparative study of the moderating effects by relational characteristics (i.e., close friend/family member with a disability and regular versus novice spectators) reveals two positive effects and one negative impact on motivation. Bloemer and Ruyter (1998) state that those with extensive experience will be more aware of it when making an evaluation. Applying this to the present study, inspiration and knowledge acquisition are key factors because spectators of wheelchair basketball are aware that they could experience the two motivating factors. For novice spectators and those who do not have a family member or close friend with a disability, physical attractiveness had a negative effect. This is possibly because of their lack of interactions with people with disabilities; therefore, disabled sport settings may make them overwhelmed and intimidated. By considering the relational moderating effects, we could conclude that the marketing strategies will be different for those who are unfamiliar with disabled sport (i.e., novices and those who do 
not have close friends or family members with a disability) and those who are familiar with it (i.e., repeaters and those who have a friend or family member with a disability). For those who are unfamiliar with disabled sport, inspiration had an intense effect on the intention to attend the mega sporting event; this proves the uniqueness and singularity of wheelchair basketball. Focusing more on inspiration, such as advertisements based on messages given by athletes with a disability, could motivate those who have never been to the venue to spectate.

On the contrary, four motivating factors (supercrip image, violence and aggression, escape, and social interaction) did not provide any significant effects toward attending the Tokyo 2020 Summer Games. This could be explained by the fact that these factors, except for supercrip image, could act as an alternative for non-disabled sport, such as basketball. Spectators who watch disabled sport are stimulated by the inherent advantage of wheelchair sport. For example, inspiration, physical skill, and physical attractiveness are extracted from the athlete itself, and acquisition of knowledge is also different from the non-disabled sport. However, supercrip image was disabled as an original facet for disabled sport by Cottingham et al. (2014); nevertheless, it did not execute toward the dependent variable. For future research, additional statistical tests should be conducted by discussing the statements of supercrip image items.

This study focuses on the factors motivating wheelchair basketball spectators and the moderating effects on the intention to attend the Tokyo 2020 Summer Games. Given the limited number of studies focusing on disabled sport from a sport marketing perspective, this study provides empirical evidence from both theoretical and practical viewpoints. Nevertheless, to ensure that research on the topic continues till 2020 and thereafter, it is necessary to address the issue of discriminant validity. Although the convergent validity met the threshold value, it was low in comparison to the general ones. For disabled sport to flourish in the sport marketing context, it is necessary to focus sharply on the validity of the MSDSC scale.

\section{Acknowledgments}

This research was supported by The Nippon Foundation Paralympic Support Center.

\section{References}

Ashton-Shaeffer, C., Gibson, H., Holt, M., and Willming, C. (2001). Women's resistance and empowerment through wheelchair sport. World Leisure J., 43(4), 11-21.

Azrena. (2017) https://azrena.com/post/7236/ (accessed 2019-02-03) (in Japanese)

Bollen, K. A. (1989). A new incremental fit index for general structural equation models. Soc., 17(3), 303-316.

Bloemer, J. and De Ruyter, K. (1998). On the relationship between store image, store satisfaction and store loyalty. Euro. J. Mark., 32(5/6): 499-513.

Byon, K. K., Cottingham, M., and Carroll, M. S. (2010). Marketing murderball: the influence of spectator motivation factors on sports consumption behaviours of wheelchair rugby spectators. Int. J. Sports Mark. Sponsorship, 12: 71-89.

Cottingham, M., Carroll, M. S., Phillips, D., Karadakis, K., Gearity, B. T., and Drane, D. (2014). Development and validation of the motivation scale for disability sport consumption. Sport Manage. Rev., 17: 49-64.

Cottingham, M., Chatfield, S., Gearity, B. T., Allen, J. T., and Hall, S. A. (2012). Using points of attachment to examine repatronage and online consumption of wheelchair rugby spectators. Int. J. Sport Manage., 13: 160-172.

Dietz-Uhler, B., Harrick, E. A., End, C., and Jacquemotte, L. (2000). Sex differences in sport fan behavior and reasons for being a sport fan. J. Sport Beha., 23: 219-231.

Fornell, C. and Larcker, D. F. (1981). Evaluating structural equation models with unobservable variables and measurement error. J. of Mark. Res., 18 (1): 39-50.

Funk, D. C., Mahony, D. F., Nakazawa, M., and Hirakawa, S. (2001). Development of the sport interest inventory (SII): Implications for measuring unique consumer motives at team sporting events. Int. J. Sports Mark. Sponsorship, 3: 38-63.

Gliedman, J. and Roth, W. (1980). The unexpected minorityHandicapped children in America. Int. J. Rehabilitation Res., 3: 601-604.

Hair, J. F., Black, W. C., Babin, B. J., and Anderson, R. E. (2010). Multivariate data analysis (pp. 708-709). New Jersey: Pearson.

Homburg, C. and Giering, A. (2001). Personal characteristics as moderators of the relationship between customer satisfaction and loyalty—an empirical analysis. Psychol Mark., 18: 43-66.

Hu, L. T. and Bentler, P. M. (1999). Cutoff criteria for fit indexes in covariance structure analysis: Conventional criteria versus new alternatives. Structural equation modeling: a multidisciplinary J. 6: 1-55.

Kwon, H. and Trail, G. (2001). Sport fan motivation: A comparison of American students and international students. Sport Mark. Q., 10: 147-155.

Matsuoka, H. (2012). Understanding the Sports Industry $5^{\text {th }}$ ed. (pp. 86). Tokyo: Kyorin Shoin.

Mittal, V. and Kamakura, W. A. (2001). Satisfaction, repurchase intent, and repurchase behavior: Investigating the moderating effect of customer characteristics. J. Mark. Res., 38: 131-142.

Ministry of Health, Labour, and Welfare (2018) https://www. 
mhlw.go.jp/content/12601000/000341558.pdf (accessed2019-02-03) (in Japanese)

Saad, G. and Gill, T. (2000). Applications of evolutionary psychology in marketing. Psychol Mark., 17: 1005-1034.

Seiders, K., Voss, G. B., Grewal, D., and Godfrey, A. L. (2005). Do satisfied customers buy more? Examining moderating influences in a retailing context. J. Mark., 69: 26-43.

Shapiro, D. R., Pitts, B., Hums, M. A., and Calloway, J. (2012). Infusing disability sport into the sport management curriculum. Sport Manage. Int. J. 8: 101-118.

Shapiro, D. R. and Pitts, B. G. (2014). What little do we know: Content analysis of disability sport in sport management literature. J. Sport Manage., 28: 657-671.

Tokyo Metropolitan Government. (2018) http://www.metro. tokyo.jp/tosei/hodohappyo/press/2018/01/30/documents/ 01_00.pdf (accessed 2018-06-25). (in Japanese)

Trail, G. and James, J. (2001). The motivation scale for sport consumption: Assessment of the scale's psychometric properties. J. Sport Behav, 24: 108-127.

Thrash, T. M. and Elliot, A. J. (2003). Inspiration as a psychological construct. J. Pers Soc Psychol, 84: 871-889.

Velazquez, B. M., Blasco, M. F., Saura, I. G., and Contri, G. B. (2010). Causes for complaining behaviour intentions: the moderator effect of previous customer experience of the restaurant. J. Services Mark., 24: 532-545.

Verhoef, P. C., Franses, P. H., and Hoekstra, J. C. (2002). The effect of relational constructs on customer referrals and number of services purchased from a multiservice provider: does age of relationship matter?. J. Academy Mark. Sci, 30: 202-216.

Yoshida, M. and Gordon, B. (2012). Who is more influenced by customer equity drivers? A moderator analysis in a professional soccer context. Sport Manage. Rev, 15: 389-403.

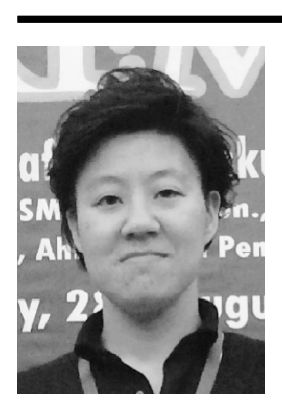

Name:

Rei Yamashita

Affiliation:

Assistant Professor, Faculty of Human

Life Design, Toyo University

Address:

48-1, Oka, Asaka-shi, Saitama, 351-8510, Japan

Brief Biographical History:

2016- Current Assistant Professor at Toyo University

2013-2016 Waseda University, Doctoral Degree of Sport

Sciences

2011-2013 Waseda University, Master's Degree of Sport

Sciences

2006-2010 Tokai University, Bachelor of Physical Education

Main Works:

-Yamashita, R., Erika Y., and Munehiko H. (2018) Motivational Differences of Attending a Sporting Event: Comparison of Local Residents and Non-Residents. Int. J. Sport Health Sci., 16, 220-230.

-Yamashita, R. (2016) Prospects for Spot Tourism Research Overviewing from Mega Sport Events: Focusing on Sport events Held in the Last 6 Years. J. Hum. Life Design, 12, 155-166.

-Yamashita, R. and Harada, M. (2015) Constraints of Sport Spectators: Focusing on J. League Division 2 Spectators, Asian Sport Manage. Rev., 9, 37-54.

Membership in Learned Societies:

- Japanese Association for Sport Management

-Asian Association for Sport Management

- Japanese Society of Sports Industry 